\title{
FINANCIAMENTO E GASTO PÚBLICO NA EDUCAÇÃO BÁSICA NO BRASIL: 1995-2005
}

\author{
Jorge AbraHÃo DE CASTRO
}

\begin{abstract}
RESUMO: Este trabalho dimensiona e analisa o gasto em educação básica; em que níveis e modalidades foram aplicados os recursos; a responsabilidade de cada ente federado pelo gasto educacional; e a prioridade econômica voltada à educação. De modo geral, constatou-se que o sistema de financiamento dos gastos das políticas de educação conseguiu manter sua proteção contra cortes orçamentários, mas, em contrapartida, não permitiu ampliação da importância macroeconômica dos gastos da área educacional, revelando baixa prioridade de governo à educação. Além disso, foi possível verificar que a educação básica é muito importante na composição dos gastos educacionais, principalmente o ensino fundamental e que grande parte das açôes governamentais tem caráter descentralizado.

Palavras-chave: Educação Básica. Financiamento da educação. Gasto da educação. Sistema educacional.
\end{abstract}

Public funding AND EXPENDITURES FOR BASIC EDUCATION IN BRAZIL: $1995-2005$

ABSTRACT: This paper helps identifying the amount of public expenditures allotted to basic education, the amount of resources applied to each education level and modality, the weight of each government level in public education funding and the priority given to education within the public budget. It shows that: 1) although the educational funding system has been spared from budget cuts, education expenditures have not increased their macroeconomic importance within the total public expenditures, which evidences that the government gives low priority to education; 2) most of the public

Doutor em Ciência Econômica, professor da Universidade de Brasília (UNB) e coordenador de pesquisa do Instituto de Pesquisa Econômica Aplicada (IPEA). E-mail: jorge.abrahao@ipea.gov.br 
educational expenditures are allotted to basic education, and more particularly to fundamental education; and finally 3) a great part of the government actions have been decentralized to the local level.

Key words: Basic education. Education funding. Expenditures for education. Educational system.

\section{Introdução}

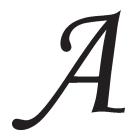

educação, ao situar-se no âmbito das responsabilidades do Estado, compondo o núcleo central dos atuais sistemas de proteção social, absorve recursos que são principalmente arrecadados de forma impositiva ao cidadão pelo Estado. Esses recursos, ao propiciar as principais condições materiais para viabilizar a formulação e implementação das políticas educacionais, podem ser um limite e um obstáculo ao atendimento das necessidades e demandas por educação. Além do gasto público, ressalta-se que o financiamento e o gasto com educação no país, também, são realizados pelas empresas e pelas famílias, ${ }^{1}$ no entanto esse item não será tratado neste trabalho.

Atualmente estão na agenda política a necessidade de ampliação do acesso e a melhoria da qualidade educação, principalmente da educação básica; respondendo em parte esse imperativo, foi aprovada a mudança na estrutura de financiamento da educação básica, com o Fundo de Manutenção e Valorização da Educação Básica (FUNDEB), que poderá trazer fortes impactos de longo prazo para a área de educação. Este texto procura contribuir para o desenvolvimento dessa agenda, mediante a identificação e compreensão de: quanto foi gasto em educação; em que níveis e modalidades foram aplicados os recursos; quem foi o ente federado responsável pelo gasto para produzir os bens e serviços educacionais; e o que isso representou em termos de prioridade de governo e esforço público.

Para tanto, se considerou importante estudar a relevância que os governos, do período histórico escolhido, têm dado à área de educação e, em particular, à educação básica. Isso porque se tem constatado a predominância de um discurso político, principalmente das classes dirigentes dos governos federal, estaduais e municipais que coloca a educação no centro das prioridades. Portanto, se tal prioridade existe, ela deveria se manifestar em termos de gastos públicos, principalmente em 
sua representação econômica, o que permite analisar a importância dessa área social no contexto da economia. É, portanto, a partir dessa preocupação que este trabalho apresenta uma série de dados e informações sobre o financiamento e o gasto da educação básica.

Para efetuar esta análise, utilizou-se a metodologia desenvolvida na Diretoria de Estudos Sociais (DISOC) do Instituto de Pesquisa Econômica e Aplicada (IPEA) para dimensionamento do gasto social, que foi adaptada exclusivamente para a área de educação. Tomou-se como período a ser investigado os anos de 1995 a 2005, que retratam o período pós-Plano Real, no qual não ocorreram mudanças de moeda, o que torna os dados de gasto e de receitas mais confiáveis para serem analisados, principalmente em comparações entre exercícios distintos.

Para tratar o problema este texto está organizado em quatro partes. Primeiramente, apresentam-se os elementos conceituais necessários para a estimação dos gastos educacionais. Em segundo, são estimados e analisados os resultados obtidos em termos de valores correntes e corrigidos do gasto educacional. A análise da evolução do Gasto Público em Educação (GPEdu) e em educação básica se inicia em seguida, com a apresentação da suas trajetórias em relação ao Produto Interno Bruto (PIB), indicando a prioridade macroeconômica do gasto educacional. $\mathrm{Na}$ quarta parte se confronta o gasto em educação e, em especial, na educação básica com a Carga Tributária, visto ser esta a principal fonte de financiamento dos gastos educacionais. Breves considerações gerais concluem este trabalho.

1. Aspectos metodológicos para o dimensionamento do gasto público em educação

Para efetuar o dimensionamento e análise dos gastos educacionais é importante adotar um conceito organizador do que pode ser compreendido como programas e ações públicas de educação. Seguiuse aqui o entendimento de que a política educacional, que determina os gastos, é composta por um conjunto de programas e ações do Estado, com o objetivo de atender às necessidades e aos direitos educacionais da população brasileira.

Um sistema educacional apresenta diversas ações e programas que absorvem recursos, que podem representar significativa parcela do PIB e 
são financiados por uma série de tributos e outras fontes de recursos. Em sua trajetória histórica, cada sociedade incorpora o reconhecimento de determinadas necessidades educacionais e que o Estado deva assumir certa responsabilidade de resposta. Tais processos constituem, em cada país, sistemas educacionais com maior ou menor abrangência, mas que são dinâmicos, estando na maior parte do tempo em construção ou em reforma. Além disso, a educação pública, em estruturas federativas, faz com que cada ente federado tenha responsabilidade e competência pela manutenção e expansão de seu sistema de ensino.

Uma definição mais ampla de gasto educacional incluiria tanto as atividades do setor público quanto as levadas a cabo pelo setor privado da economia, compreendendo o emprego de recursos próprios das famílias, empresas privadas e organizações não-governamentais. Para estudar especificamente a atuação do Estado, aplica-se o conceito de Gasto Público Educacional (GPEdu), que compreende os recursos financeiros brutos empregados pelo setor público no atendimento das necessidades e direitos educacionais e que corresponde ao custo de bens e serviços - inclusive bens de capital - e transferências, sem deduzir o valor de recuperação - depreciação e amortização dos investimentos em estoque ou recuperação do principal de empréstimos anteriormente concedidos.

Para se obter os dados necessários a este trabalho segue-se a metodologia para apuração do gasto social da DISOC do IPEA, ${ }^{2}$ em que é central a idéia de Area de Atuaçãa ${ }^{3}$ como conceito que orienta o agrupamento das despesas de caráter social segundo um critério de objetivo ou finalidade dos gastos. Esse é um esforço de promover a melhor aproximação possível da destinação efetiva dos dispêndios junto da população beneficiária. Esse conceito não se enquadra nas classificações funcionais ou institucionais geralmente utilizadas em estudos sobre os dispêndios do governo federal; a forma de agregação do gasto público vai além de um mero registro de despesas por órgão setorial - critério institucional -, bem como de um simples levantamento de despesas por funçóes ou programas - enfoque funcional-programático.

Ao se adotar a metodologia mencionada à educação será compreendida como uma Área de Atuação, onde se computam todas as despesas $^{4}$ com formulação da política setorial e a manutenção, expansão e melhoria de escolas de diversos níveis e modalidades de ensino, que comporão as principais subáreas de atuação: educação infantil, ensino fundamental, ensino médio e profissionalizante, ensino superior e 
outros gastos - entre os quais se incluem os gastos com a educação especial, educação indígena e educação física e desporto. Os recursos do ensino supletivo e educação de jovens e adultos foram diluídos entre o ensino fundamental e o médio. $\mathrm{Na}$ área de educação, também, se incluem instituições militares de ensino regular - médio e superior abertas ao ingresso público, mas excluem aquelas voltadas somente para a formação de servidores civis ou militares, estabelecimentos de educação física e desporto e programas de assistência a estudantes. Em contrapartida, é importante salientar que não estão sendo consideradas como gasto de educação as despesas com: alimentação escolar (merenda escolar); hospitais de ensino; e os benefícios a servidores públicos da área de educação, tais como as aposentadorias e pensões. Esses gastos são considerados em outras Áreas de Atuação.

A organização das subáreas se baseou na descrição programática examinada em cada unidade orçamentária e, no patamar mais analítico da classificação funcional-programática, na descrição da ação orçamentária. Salienta-se que a análise do trabalho procura cobrir tanto as ações educacionais da administração direta, quanto aquelas desenvolvidas e executadas por órgãos da administração indireta que dispõem de recursos próprios. Assim, evitou-se a perda de informações das entidades com atuação educacional descentralizada da administração.

Por fim, chama-se a atenção do leitor para o fato de que foi necessária a estimação dos gastos para alguns níveis e modalidades educacionais em alguns anos do período, principalmente para os municípios. ${ }^{5}$ Por isso, é importante salientar as limitações da estimação de parâmetros que obviamente não conseguem cobrir todas as especificidades que as variações reais exigiriam. Como em grande parte dos trabalhos do gênero, torna-se necessária a utilização de certo grau de arbitrariedade para a montagem das estimativas para os parâmetros utilizados. Apesar disso, acredita-se estar fornecendo uma medida relativa aceitável das modificaçôes recentes na estrutura e na responsabilidade da execução dos gastos, sendo mais importante observar a tendência do que os valores propriamente ditos.

\section{Gasto público na educação básica brasileira}

Os resultados da utilização dos conceitos mencionados no item anterior permitiram fazer a estimação do gasto educacional que é 
apresentado na Tabela 1. Os valores apresentados estão deflacionados para 2005, pelo IPCA médio. A utilização do valor corrigido permite se ter uma idéia da evolução do gasto, descontando-se os valores que representam apenas correção e manutenção do poder de compra do gasto que foi efetuado.

\section{Tabela 1}

(Gasto da total em Educação e na Educação Básica, em valor constante:

1995-2005)

\begin{tabular}{|c|c|c|c|c|c|c|c|c|c|c|c|}
\hline Discriminação & 1995 & 1996 & 1997 & 1998 & 1999 & 2000 & 2001 & 2002 & 2003 & 2004 & 2005 \\
\hline \multicolumn{12}{|c|}{ Valores constantes para 2005, IPCA médio (RS billhões) } \\
\hline Educação Básica & 45,0 & 47,2 & 44,6 & 53,7 & 54,4 & 54,1 & 58,1 & 60,9 & 60,4 & 65,2 & 66,6 \\
\hline Ensino Fundamental & 33,1 & 35,0 & 32,2 & 40,5 & 40,2 & 40,7 & 43,9 & 46,0 & 46,8 & 50,2 & 51,2 \\
\hline Ensino Médio & 5,8 & 6,2 & 6,4 & 7,3 & 7,9 & 8,6 & 9,3 & 9,4 & 7,9 & 8,9 & 9,1 \\
\hline Outros gastos & 16,4 & 14,9 & 15,2 & 15,1 & 15,7 & 17,3 & 17,2 & 17,6 & 16,6 & 18,4 & 20,4 \\
\hline Outros & 2,7 & 2,4 & 2,3 & 3,2 & 3,0 & 4,1 & 3,7 & 3,9 & 3,8 & 4,6 & 5,4 \\
\hline Total & 61,4 & 62,1 & 59,8 & 68,8 & 70,0 & 71,4 & 75,3 & 78,5 & 77,1 & 83,7 & 87,0 \\
\hline \multicolumn{12}{|c|}{ Valor percentual de cada nível educacional e demais gastos na área de educação (\%) } \\
\hline Educação Básica & $73,3 \%$ & $76,1 \%$ & $74,7 \%$ & $78,0 \%$ & $77,6 \%$ & $75,8 \%$ & $77,2 \%$ & $77,6 \%$ & $78,4 \%$ & $77,9 \%$ & $76,6 \%$ \\
\hline Educação da Criança de 0 a 6 Anos & $9,9 \%$ & $9,8 \%$ & $10,2 \%$ & $8,6 \%$ & $8,9 \%$ & $6,6 \%$ & $6,6 \%$ & $7,1 \%$ & $7,3 \%$ & $7,4 \%$ & $7,1 \%$ \\
\hline Outros & $4,3 \%$ & $3,9 \%$ & $3,8 \%$ & $4,7 \%$ & $4,2 \%$ & $5,7 \%$ & $4,9 \%$ & $5,0 \%$ & $4,9 \%$ & $5,5 \%$ & $6,2 \%$ \\
\hline Total & $100,0 \%$ & $100,0 \%$ & $100,0 \%$ & $100,0 \%$ & $100,0 \%$ & $100,0 \%$ & $100,0 \%$ & $100,0 \%$ & $100,0 \%$ & $100,0 \%$ & $100,0 \%$ \\
\hline
\end{tabular}

Fonte: IPEA/DISOC; IBGE; SIAFI/STN.

Observação: Os dados originais para os gastos públicos em educação do Governo Federal (em todos os níveis e modalidades) de 1995 até 2005 foram obtidos de Castro et. alli (2007). Os dados originais para os gastos públicos em educação dos demais entes federados (em todos os níveis e modalidades) de 1995 até 1999 foram obtidos de Almeida (2001). Os gastos de 2000 a 2005 dos governos estaduais estão com base nos resultados apresentados nos Balanços Gerais dos estados e DF e disponibilizados pela Secretaria do Tesouro Nacional (STN) para a Lei de Responsabilidade Fiscal (LRF). Os gastos de 2000 a 2005 para os municipios representam projeções efetuadas pelo autor, com base nos resultados apresentados pela Secretaria do Tesouro Nacional (sTN) para a Lei de Responsabilidade Fiscal (LRF), e na dinâmica da arrecadação tributária do período.

Os gastos em educação realizados pelas três esferas de governo, que são apresentados na Tabela 1 , mostram que houve uma ampliação e ganho de importância, em termos relativos, no período transcorrido de 1995 a 2005, quando saíram de $\mathrm{R} \$ 61,4$ bilhões para $\mathrm{R} \$ 87,0$ bilhões, o que representou um crescimento real de $42 \%$. No entanto, observam-se dois movimentos: um entre 1995 e 1997, no qual se pode observar até mesmo uma queda no valor gasto, já no restante do período os gastos anuais se ampliam continuamente.

Considerando apenas a educação básica, os dados apresentados na tabela demonstram a elevação quase permanente dos valores gastos, que 
saem de $\mathrm{R} \$$ 45,0 bilhões, em 1995, para $\mathrm{R} \$$ 66,6 bilhões, em 2005, o que significou que em 11 anos houve um crescimento, em termos reais, de $48 \%$, denotando um crescimento médio real de 3,3\% ao ano (Gráfico 1). Esse crescimento não ocorreu de forma constante - houve anos em que os aumentos giraram em torno de $9,4 \%$ e outros em que atingiram apenas $1,5 \%$. Teve influência na trajetória dos gastos a criação do Fundo de Manutenção e Desenvolvimento do Ensino Fundamental e de Valorização do Magistério (FUNDEF) - criado em 1996 pela Emenda Constitucional n. 14 e regulamentado pela Lei n. 9.424/96 -, que introduziu uma forma inovadora de repartição dos recursos para o ensino fundamental, principalmente ao estipular uma equalização do valor do gasto por aluno/ano com base em um indicador educacional - a matrícula.

Além disso, os valores não se mostram sempre crescentes ou estáveis quando são analisados de forma desagregada por subáreas de atuação - visto que ocorrem movimentos muitas vezes irregulares (ver Tabela 1). Essa trajetória dos gastos está relacionada principalmente à configuração política e institucional que se molda em cada subárea, que depende da luta política que é travada no interior do sistema educacional e nos embates com o setor econômico, que define os limites a as opções de ação governamental.

\section{Gráfico 1}

(Evolução do gasto na Educação Básica, em valor constante: 1995-2005)

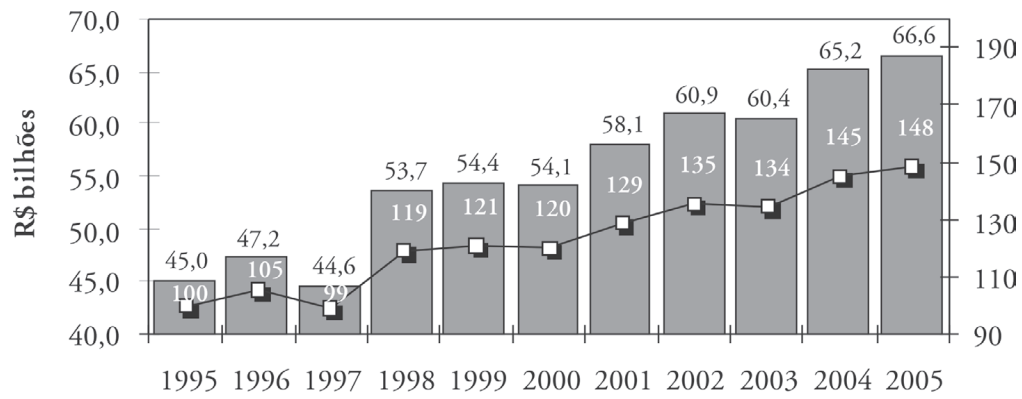

Gasto na educação básica (IPCA médio 2005) - $\square$ N. Índice $(1995=100)$

Fonte: DISOC/IPEA e IBGE

Educ. Soc., Campinas, vol. 28, n. 100 - Especial, p. 857-876, out. 2007 
Tomando-se o volume de recursos que foi aplicado a cada ano nas políticas educacionais e construindo o Gráfico 2 - mostra-se apenas dois anos do período, como forma de facilitar a exposição -, ressalta-se que o núcleo da política educacional foi permanentemente localizado ao longo do tempo na subárea do ensino fundamental. Além disso, observa-se que houve, de fato, alteração expressiva e positiva para os gastos com o ensino fundamental e ensino médio, enquanto as demais alterações foram modestas. Quando se considera o conceito de educação básica, os gastos atingem algo em torno de $77 \%$ do GPEdu, apesar de a participação de cada uma das subáreas que o compõem modificar-se durante o período (ver Tabela 1).

\section{Gráfico 2}

(Gastos das subáreas da Educação, em valor constante: 1995 e 2005)

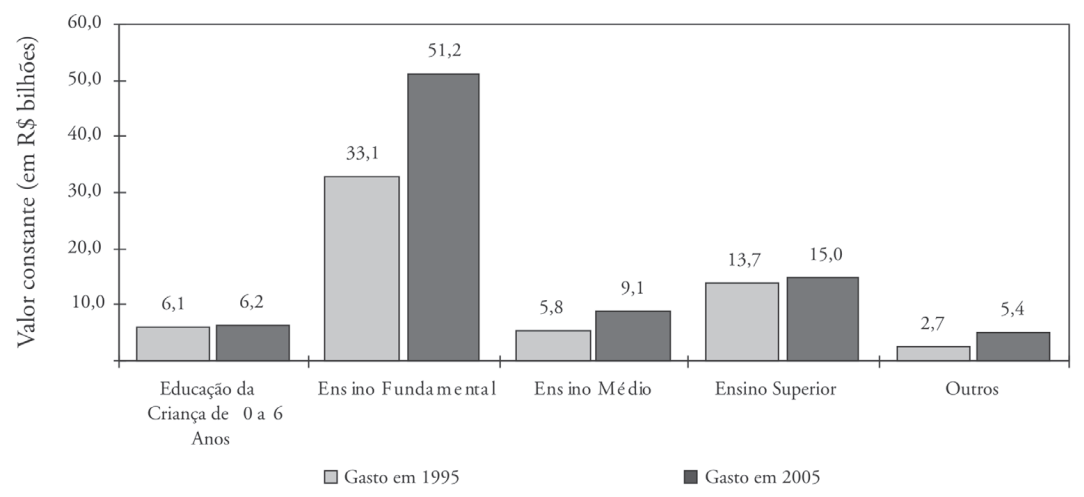

Fonte: DISOC/IPEA

No caso do ensino superior, o fator preponderante para a explicação da trajetória observada é a política de compressão salarial do funcionalismo público vigente na gestão FHC e reaplicada no primeiro ano da gestão Lula, com o aumento de apenas $0,1 \%$ para os servidores públicos. Ressalta-se que grande parte dos gastos das Instituiçóes Federais de Ensino Superior (IFES) é realizada com pagamento de pessoal e encargos sociais, sejam ativos ou inativos. Além disso, há também considerável restrição aos investimentos e às demais despesas correntes na gestão. 
A estimação do gasto público por esfera de governo (União, Estados, Distrito Federal e Municípios) também é um elemento importante para se medir e comparar o grau de responsabilidade pela oferta dos bens e serviços educacionais. A seguir, na Tabela 2, procura-se mostrar essas evidências apenas para a educação básica. Os valores que são apresentados indicam que a distribuição entre esferas dos gastos da educação básica é bastante descentralizada. Os grandes responsáveis pelos gastos são os estados e municípios, os quais, em conjunto, responderam na média do período por 93,9\% dos dispêndios. Estima-se que esse valor expressa um nível de comprometimento desses governos com a educação básica, de algo em torno de $20 \%$ de seus gastos totais diretos.

\section{Tabela 2}

(Gasto em Educação Básica por esfera de governo, em valor constante: 1995-2005)

\begin{tabular}{|c|c|c|c|c|c|c|c|}
\hline \multirow{3}{*}{ Ano } & \multicolumn{4}{|c|}{ Valores constantes para 2005, IPCA médio ( $\mathrm{R} \$$ bilhões) } & \multicolumn{3}{|c|}{ Relações (\%) } \\
\hline & \multicolumn{3}{|c|}{ Unidade Federada } & \multirow{2}{*}{$\begin{array}{l}\text { Total } \\
\text { (d) }\end{array}$} & \multirow[b]{2}{*}{$(\mathrm{a} / \mathrm{d})$} & \multirow[b]{2}{*}{$(\mathrm{b} / \mathrm{d})$} & \multirow[b]{2}{*}{$(\mathrm{c} / \mathrm{d})$} \\
\hline & $\begin{array}{c}\text { Municípios } \\
\text { (a) }\end{array}$ & $\begin{array}{c}\text { Estados e DF } \\
\text { (b) }\end{array}$ & $\begin{array}{l}\text { União } \\
\text { (c) }\end{array}$ & & & & \\
\hline 1995 & 16,7 & 24,6 & 3,6 & 45,0 & 37,2 & 54,7 & 8,1 \\
\hline 1996 & 17,3 & 26,8 & 3,2 & 47,2 & 36,5 & 56,6 & 6,9 \\
\hline 1997 & 17,0 & 25,1 & 2,5 & 44,6 & 38,1 & 56,2 & 5,7 \\
\hline 1998 & 22,0 & 28,1 & 3,5 & 53,7 & 41,0 & 52,4 & 6,6 \\
\hline 1999 & 24,5 & 26,7 & 3,2 & 54,4 & 45,0 & 49,0 & 6,0 \\
\hline 2000 & 24,9 & 25,4 & 3,8 & 54,1 & 46,1 & 46,9 & 7,0 \\
\hline 2001 & 26,4 & 27,7 & 4,1 & 58,1 & 45,4 & 47,6 & 7,0 \\
\hline 2002 & 29,4 & 28,3 & 3,3 & 60,9 & 48,2 & 46,4 & 5,4 \\
\hline 2003 & 30,2 & 27,1 & 3,1 & 60,4 & 49,9 & 44,9 & 5,2 \\
\hline 2004 & 33,1 & 29,0 & 3,2 & 65,2 & 50,7 & 44,4 & 4,9 \\
\hline 2005 & 33,0 & 30,6 & 3,0 & 66,6 & 49,6 & 46,0 & 4,5 \\
\hline
\end{tabular}

Fonte: IPEA/DISOC, IBGE/MP, INEP/MEC e Almeida (2001). Elaboração: J.A. Castro.

Além disso, os dados mostram que a manutenção do volume de gastos em favor da educação básica pelos municípios foi se ampliando continuamente, denotando uma ampliação da responsabilidade deste ente federado. Neste sentido, no período analisado os municípios ampliaram sua participação relativa de $37,2 \%$ para $49,6 \%$, demonstrando que houve uma municipalização. Em contrapartida, os estados reduziram sua 
participação de 54,7\% para cerca de 46\%. Enquanto isso, a União continua apresentando baixa participação: demonstrou, inclusive, queda de $8,1 \%$ para apenas $4,5 \%$.

Os dados demonstram que as esferas de governo assumiram as determinações decorrentes da atual Constituição Federal brasileira, que atribuem aos estados e municípios a responsabilidade pela oferta da educação básica. Por outro lado, o governo federal buscou cumprir uma função supletiva com baixa aplicação de recursos; assim, a maior parte dos recursos aplicados pelo governo federal, na área da educação, destina-se ao custeio das IFES, escolas técnicas federais e centros federais de ensino tecnológico (CEFETs).

\section{Gasto público em educação e política econômica}

Esta seção tem como objetivo apresentar e analisar a trajetória do GPEdu, à luz das tensões econômicas no período que vai de 1995 a 2005. Busca-se, principalmente neste momento, mensurar e compreender as restrições enfrentadas pela política educacional, principalmente a de educação básica, diante dos movimentos mais gerais a que foi submetida a economia brasileira no período. Para realizar esta análise, os dados serão apresentados em termos de percentuais do Produto Interno Bruto (PIB), que foi recentemente recalculado pelo Instituto Brasileiro de Geografia e Estatística (IBGE). Para a relação mais agregada, os resultados estão na Tabela 3 .

A primeira constatação é de que, contrariamente ao que foi demonstrado na seção anterior, pode se considerar que não houve crescimento do GPEdu quando comparado com o PIB, pois o indicador (GPEdu/ PIB) passou de 4,01\%, em 1995, para apenas 4,05\%, em 2005. Portanto, em 11 anos a política educacional dos diferentes entes federados elevou sua participação na renda nacional em apenas 0,04 pontos percentuais (p.p.) do PIB - o que representa um crescimento de apenas $1 \%$. Isso evidencia que o crescimento do gasto educacional foi apenas equivalente ao crescimento da economia brasileira como um todo. Além disso, como mostra o Gráfico 3, tem um caráter pró-cíclico em toda a trajetória do período.

Além do mais, observam-se dois movimentos: um entre 1995 e 1997, no qual se pode perceber uma queda constante da participação 


\section{Tabela 3}

(Gasto em Educação Básica e no total da área de Educação - GPEdu- em relação ao PIB: $1995-2005)$

\begin{tabular}{|c|c|c|c|c|c|c|}
\hline \multirow{2}{*}{ Ano } & \multicolumn{3}{|c|}{ Educação Básica } & \multicolumn{3}{c|}{ Total da área de Educação (GPEdu) } \\
\cline { 2 - 7 } & $\begin{array}{c}\text { Valor em } \\
\text { relação ao } \\
\text { PIB (\%) }\end{array}$ & $\begin{array}{c}\text { N. Índice } \\
(1995= \\
100 \%)\end{array}$ & $\begin{array}{c}\text { Variação } \\
\text { anual } \\
(\%)\end{array}$ & $\begin{array}{c}\text { Valor em } \\
\text { relação ao } \\
\text { PIB (\%) }\end{array}$ & $\begin{array}{c}\text { N. Índice } \\
(1995= \\
100 \%)\end{array}$ & $\begin{array}{c}\text { Variação } \\
\text { anual } \\
(\%)\end{array}$ \\
\hline 1995 & 2,94 & 100 & - & 4,01 & 100 & - \\
1996 & 2,99 & 102 & 1,6 & 3,92 & 98 & $(2,1)$ \\
1997 & 2,71 & 92 & $(9,2)$ & 3,63 & 91 & $(7,5)$ \\
1998 & 3,22 & 110 & 19,0 & 4,13 & 103 & 13,9 \\
1999 & 3,15 & 107 & $(2,3)$ & 4,06 & 101 & $(1,9)$ \\
2000 & 3,03 & 103 & $(3,9)$ & 4,00 & 100 & $(1,5)$ \\
2001 & 3,15 & 107 & 4,0 & 4,08 & 102 & 2,1 \\
2002 & 3,16 & 107 & 0,2 & 4,07 & 102 & $(0,3)$ \\
2003 & 3,12 & 106 & $(1,1)$ & 3,98 & 99 & $(2,1)$ \\
2004 & 3,14 & 107 & 0,7 & 4,03 & 101 & 1,3 \\
2005 & 3,10 & 106 & $(1,4)$ & 4,05 & 101 & 0,4 \\
\hline
\end{tabular}

Fonte: IPEA/DISOC, IBGE/MP, INEP/MEC e Almeida (2001). Elaboração: J. A. Castro.

relativa, caindo de 4,01\% para 3,67\% do PIB. Esse movimento pode ser explicado pelo fato de o PIB, nesse sub-período, ter crescido mais rapidamente que os gastos em educação. Isso significa que a área de educação não foi beneficiada por um maior aporte de recursos quando ocorreu crescimento; em contrapartida, no outro movimento, ocorrido nos dois anos seguintes, momento em que o crescimento foi bastante reduzido, observa-se uma melhoria no valor do indicador $(4,13 \%$ e $4,06 \%$ do PIB). Por esses dados, observa-se que a área ampliou, mesmo que pouco, seu espaço em termos relativos, principalmente a partir de 1998, coincidentemente, ano da implantação do FUNDEF, quando a importância relativa sobe em cerca de $0,5 \%$ do PIB, mas não consegue se manter neste patamar nos anos posteriores. No entanto, cabe observar que esses números podem também estar refletindo um efeito composição, 
em razão de a taxa do produto ter sido baixa, embora sinalize que a área conseguiu manter o patamar que tinha.

Portanto, não houve de fato uma prioridade macroeconômica concedida às políticas educacionais pelos governos no período; ocorreu apenas a manutenção do status quo de gasto da política educacional. Cabe salientar que se isso tivesse ocorrido com um PIB em forte crescimento, não seria de todo mal, pois os gastos educacionais poderiam ascender acima do aumento da matrícula, o que poderia representar uma possibilidade de ampliação de gastos relativos e de melhoria da qualidade da educação. Entretanto, não foi isso que ocorreu no Brasil, pois foi um momento de pífio crescimento do PIB, além de ser bastante errático.

\section{Gráfico 3}

(Variação anual real do total da área de Educação - GPEdu - e do PIB, em \%: 1995-2005)

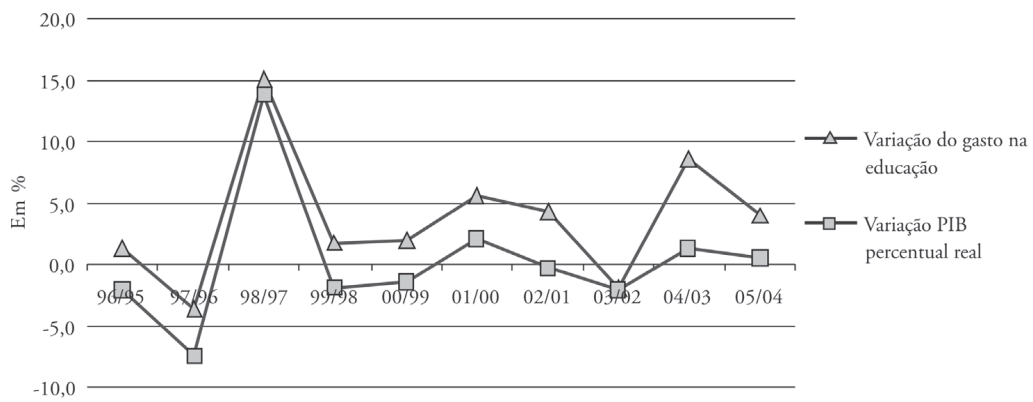

Fonte: DISOC/IPEA e IBGE

No que diz respeito à educação básica, como mostra a Tabela 3, a situação é um pouco melhor, podendo se considerar que houve crescimento do gasto quando comparado com o PIB, pois o indicador (gasto em educação básica/PIB) passou de 2,94\%, em 1995, para apenas 3,10\%, em 2005. Portanto, neste período, a educação básica dos diferentes entes federados elevou sua participação na renda nacional em apenas 0,16 p.p. do PIB - o que representa um crescimento de 6\%. Esses números refletem a prioridade que foi dada à área, principalmente ao ensino fundamental. 
A prioridade dada ao ensino fundamental é demonstrada no Gráfico 4, onde se mostra que essa subárea elevou-se do patamar de cerca de $2,16 \%$ do PIB, em 1995 , para $2,35 \%$, em 2005 - um aumento de 0,19 p.p. -, ou seja, é a que apresentou maior crescimento no período (ver Gráfico 4). Além dessa subárea, cresceram também, mas em menor escala, o ensino médio e os outros gastos educacionais.

\section{Gráfico 4}

(Gastos das subáreas da Educação, em relação ao PIB: 1995 e 2005)

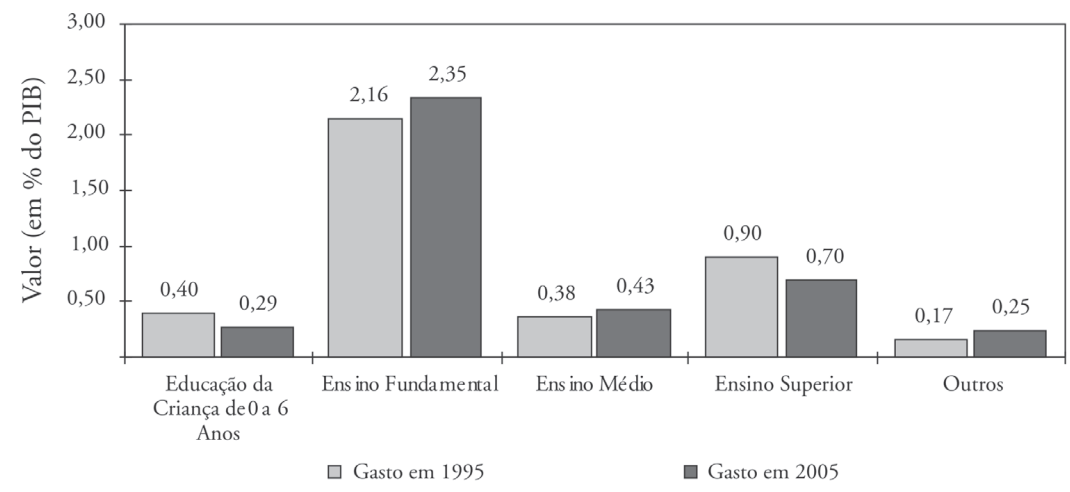

Fonte: DISOC/IPEA

Em contrapartida, houve perda de importância para as subáreas de ensino superior e para a educação infantil, ou seja, essas subáreas não tiveram aporte de recursos compatível com o crescimento econômico do período, mesmo ele sendo pífio. Esses resultados decorrem do fato de que, neste período, o ensino superior esteve em constante ataque e sujeito permanente a cortes de recursos pelos setores econômicos do governo, além de revelar a permanente ausência de prioridade e falta de compreensão da importância da educação infantil que até hoje vigora no país.

Pode-se concluir, após examinar esses dados, que a não ampliação da importância dos gastos em educação demonstra, claramente, o sentido do ajuste macroeconômico imposto à sociedade brasileira, sobretudo no período de crise da política de estabilização monetária. Por 
isso, em todo o período, a prioridade macroeconômica da área de educação pouco se alterou, apesar do discurso em prol da educação. Por outro lado, isso que aconteceu com a educação, como mostram Castro et al. (2007), reflete a opção de política econômica que tem levado à imensa transferência de renda - do lado real da economia para o financeiro - e que se processa mediante apropriação de parcela expressiva do gasto público; o que reflete a primazia dos interesses de determinados setores político-econômicos, ligados principalmente à área financeira.

\section{Gasto em educação básica e Carga Tributária Bruta}

O financiamento público do gasto educacional ocorre mediante a utilização de diversas fontes de recursos que o Estado pode recolher da sociedade. Essas fontes de recursos podem ser divididas em dois grandes tipos: fontes tributárias - impostos, taxas e contribuiçōes econômicas e sociais -, que são recursos de origem impositiva; e fontes não-tributárias - títulos do tesouro, recursos diretamente arrecadados, operações de créditos e outros.

No caso da educação, Castro e Sadeck (2003) já demonstraram a grande importância dos recursos provenientes da arrecadação tributária. Mostraram ainda que os recursos de impostos são as principais fontes para os gastos, seguidos dos recursos do salário-educação, sendo pouco relevantes aqueles provenientes das fontes não-tributárias. Podese até dizer que, atualmente, o GPEdu é quase totalmente financiamento com recursos tributários, daí a importância de se cruzar os dados do gasto educacional com a Carga Tributária Bruta (Ств). ${ }^{6}$

Se para o GPEdu a arrecadação tributária é tão relevante, é interessante se verificar qual é o peso para o sistema tributário financiar as políticas educacionais e, também, qual é a sua dinâmica atual. Para realizar esta análise, para a educação básica, que é o objeto central deste trabalho, devem-se utilizar os dados dos gastos em educação básica e compará-los ao volume da СТВ. Na Tabela 4 são apresentados os dados do gasto em educação básica e da СТВ, originados na Secretaria da Receita Federal. ${ }^{7}$

Os resultados apresentados na tabela mostram que o gasto em educação básica subiu apenas 0,16 p.p. do PIB no período de 1995 a 


\section{Tabela 4}

(Gasto em Educação Básica e Carga Tributária Bruta no Brasil: 1995-2005)

\begin{tabular}{|c|c|c|c|c|c|c|c|}
\hline \multirow{3}{*}{ Ano } & \multicolumn{2}{|c|}{$\begin{array}{l}\text { Gasto em educação } \\
\text { básica (\% do PIB) }\end{array}$} & \multicolumn{3}{|c|}{$\begin{array}{l}\text { Carga Tributária } \\
\text { (\% do PIB) }\end{array}$} & \multicolumn{2}{|c|}{ Relaçōes } \\
\hline & \multirow{2}{*}{$\begin{array}{l}\text { Federal } \\
\text { (a) }\end{array}$} & \multirow{2}{*}{$\begin{array}{l}\text { Total } \\
\text { (b) }\end{array}$} & \multirow{2}{*}{$\begin{array}{c}\text { Federal }^{(1)} \\
\text { (c) }\end{array}$} & \multicolumn{2}{|c|}{ Total } & \multirow[b]{2}{*}{$(\mathrm{a} / \mathrm{c})$} & \multirow[b]{2}{*}{$(\mathrm{b} / \mathrm{d})$} \\
\hline & & & & (d) & $\begin{array}{c}\text { N. Índice } \\
(1995= \\
100 \%)\end{array}$ & & \\
\hline 1995 & 0,24 & 2,94 & 16,6 & 27,2 & 100 & 1,4 & 10,8 \\
\hline 1996 & 0,20 & 2,99 & 16,1 & 26,7 & 98 & 1,3 & 11,2 \\
\hline 1997 & 0,15 & 2,71 & 16,6 & 26,9 & 99 & 0,9 & 10,1 \\
\hline 1998 & 0,21 & 3,22 & 17,6 & 27,8 & 102 & 1,2 & 11,6 \\
\hline 1999 & 0,19 & 3,15 & 18,9 & 29,0 & 107 & 1,0 & 10,9 \\
\hline 2000 & 0,21 & 3,03 & 19,5 & 30,4 & 111 & 1,1 & 10,0 \\
\hline 2001 & 0,22 & 3,15 & 20,1 & 31,2 & 115 & 1,1 & 10,1 \\
\hline 2002 & 0,17 & 3,16 & 21,0 & 32,4 & 119 & 0,8 & 9,7 \\
\hline 2003 & 0,16 & 3,12 & 20,7 & 32,0 & 117 & 0,8 & 9,8 \\
\hline 2004 & 0,15 & 3,14 & 21,2 & 32,6 & 120 & 0,7 & 9,6 \\
\hline 2005 & 0,14 & 3,10 & 21,9 & 33,7 & 124 & 0,6 & 9,2 \\
\hline
\end{tabular}

Fonte: DISOC/IPEA e Secretaria da Receita Federal.

Nota: (1) Exclui as transferências automáticas constitucionais.

2005. Esse processo de crescimento foi bastante descontínuo durante o período; variando também a intensidade desse crescimento. Por outro lado, А Ств se ampliou muito mais neste período, em cerca de 6,5 p.p. do PIB, processo que ocorreu praticamente de forma contínua. O crescimento dos gastos em educação representou apenas $2,5 \%$ do crescimento da carga. Ou seja, se a СТв subiu não foi em virtude das necessidades relativas às políticas de educação.

Além disso, os dados da tabela também demonstram que, no caso do gasto em educação básica, de responsabilidade do governo federal, o que ocorreu foi decréscimo de 0,10 p.p. do PIB; ao mesmo tempo, 
a carga tributária de responsabilidade do governo federal se ampliou em cerca de 5,3 p.p. do PIB. Com isso, o percentual de participação do gasto federal em educação, que era de $1,4 \%$, diminui ainda mais, para apenas $0,6 \%$ de sua arrecadação. Ou seja, o governo federal é o grande responsável pela ampliação da carga tributária, mas são os estados e municípios que sustentam o crescimento da educação básica.

Observando a trajetória dos indicadores anteriores no Gráfico 5 , pode-se dizer que os gastos com educação básica são praticamente constantes e girando em torno de $3 \%$ do PIB, em todo o período analisado, enquanto se observam dois períodos distintos para a Ств. No período compreendido entre 1995 e 1998, а СТВ praticamente ficou parada e cresce apenas 0,01 p.p. do PIB. Já no período 1999 até 2005, como se observa no gráfico, a СТВ cresce em ritmo mais acentuado, enquanto, de novo, o gasto em educação básica fica parado, o que demonstra que, mesmo neste momento, esse gasto não absorveu parcela da ampliação da carga. Ou seja, novas prioridades adotadas pela política macroeconômica, principalmente os gastos financeiros do governo, forçaram esse movimento (Castro et al., 2007).

\section{Gráfico 5}

(Gasto em Educação Básica e Carga Tributária Bruta, em relação ao PIB: 1995-2005)

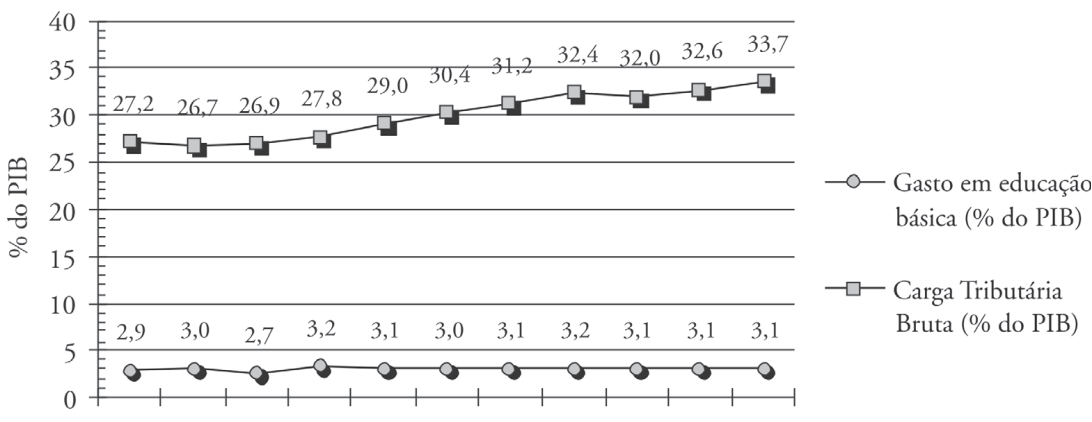

19951996199719981999200020012002200320042005

Fonte: DISOC/IPEA e Secretaria da Receita Federal. 


\section{Considerações finais}

Constatou-se que o sistema de financiamento dos gastos das políticas de educação manteve sua proteção contra cortes orçamentários, que lhe é típico, mas, em contrapartida, observou-se que o sistema não permitiu ampliação da importância macroeconômica dos gastos da área educacional. Além disso, o sistema sofreu uma reestruturação - principalmente com a criação do FUNDEF, centrado no ensino fundamental que trouxe dificuldades para o aporte de mais recursos para os outros níveis e modalidades. Por isso, os dados mostram uma queda de importância, em relação ao PIB, na educação infantil e no ensino superior. Além disso, houve, por um lado, a transferência crescente das responsabilidades para os municípios, configurando-se um processo de forte municipalização, com os estados e o governo federal perdendo importância. Por outro lado, esses dados indicam uma resposta à seguinte pergunta: Como ficou o regime de colaboração entre as esferas de governo? A resposta é que esse regime foi pouco exercido por todos no período.

As informaçôes apresentadas revelaram ainda: (i) a importância da educação básica nos gastos educacionais, reafirmando sua posição de constituir-se em um dos pilares da política educacional brasileira; (ii) o caráter descentralizado das ações governamentais da área, com estados e municípios sendo as instâncias federadas que mais se ocupam das ações de educação, respondendo pela maioria dos gastos realizados e comprometendo parcela razoável de seus recursos não-financeiros nesta direção; (iii) a pouca importância, em termos de recursos aplicados, do governo federal no financiamento da educação básica; (iii) o grande esforço de gasto público destina-se ao ensino fundamental, confirmando a prioridade política conferida a esse nível de ensino, seguido dos gastos com a educação superior, o ensino médio e a educação infantil.

Portanto, alguns desafios estão colocados para a efetiva implementação das políticas educacionais de educação básica nos próximos anos. Entre os mais importantes, está o de proteger essa política, conseqüentemente, o seu gasto diante de conjunturas econômicas e políticas adversas. Os dados revelam a colagem desses gastos ao movimento mais geral da economia, estabelecendo uma dinâmica em que ele está mais susceptível à expansão quando existe recurso orçamentário disponível e pouca restrição fiscal; e à contração, quando piora a situação financeira 
do setor público, em geral acompanhando o baixo crescimento do PIB, em conjunto com movimentos de restriçôes fiscais decorrentes de processos de ajustes.

Por fim, deve-se pensar que parte razoável das necessidades educacionais da população brasileira ainda não foi atendida, o que vai exigir a ampliação do acesso a bens e serviços educacionais existentes e a ser criados. Além disso, é necessária a promoção de melhorias na qualidade da oferta de bens e serviços públicos prestados, o que também vai exigir a ampliação do gasto em dimensão ainda a ser estimada. Neste sentido, seria importante contar com uma política macroeconômica que estivesse pautada pela proposta de um forte crescimento econômico. Mas, também, é possível pensar em uma reorientação de uma parcela do gasto público para o atendimento das necessidades educacionais, utilizando-se principalmente aquela parte do gasto que está esterilizada para remuneração da dívida pública.

\section{Recebido em julho de 2007 e aprovado em agosto de 2007.}

\section{Notas}

1. A respeito dos gastos das famílias com educação, ver recente trabalho de Castro e Vaz (2007).

2. Essa metodologia, em sua primeira versão, foi apresentada, em 1998, na Diretoria de Estudos Sociais (DISOC) do IPEA; ver Fernandes et al. (1998a) e Fernandes et al. (1998b). O objetivo geral era criar uma base de dados que permitisse o acompanhamento sistemático dos dispêndios dos governos na área social e das suas respectivas fontes de financiamento. Esta linha de pesquisa continua a ser desenvolvida nessa Diretoria, tanto no aspecto metodológico quanto em sua aplicação; a respeito, ver, principalmente, Castro et al. (2003); Castro e Cardoso (2005); Castro et al. (2007). Essa metodologia também já foi adaptada para o caso da educação; a respeito, ver Castro e Fernandes (1999).

3. De acordo com a metodologia, a divisão dos gastos por Áreas de Atuação procura alocar as açôes sociais em grupos diferenciados de acordo com atendimento às necessidades e aos direitos sociais prevalecentes nas disposições jurídico/institucionais de cada país e, também, procura facilitar a leitura e a compreensão dos rumos das políticas sociais adotadas. Este conceito permite, entre outras coisas, melhor destaque e transparência de despesas em áreas sociais atendidas por múltiplos órgãos, como saneamento, alimentação e nutrição, habitação e urbanismo; separou, pela primeira vez, os gastos com benefícios a servidores públicos (pensões e aposentadorias) dos gastos de cada área específica e de ter destacado a Previdência Geral, do Instituto Nacional do Seguro Social (INSs), da Previdência do Servidor Público, do Regime Jurídico Único.

4. As despesas aqui consideradas correspondem à despesa liquidada, o que significa que os montantes relativos ao total do exercício fiscal não incorporam os chamados Restos a Pagar. 
Estes serão considerados como desembolso efetivo no exercício em que se der sua liquidação. Vale lembrar que as despesas liquidadas correspondem ao segundo estágio da despesa e se configura quando o serviço, obra ou mercadoria contratada são de fato concluídos e entregues à administração pública.

5. Para os dados de gasto de responsabilidade do governo federal não foi necessária a realização de nenhuma proxy para distribuir recursos entre níveis e modalidades, representando de fato os gastos realizados. No entanto, no caso de estados e, principalmente dos municípios, a parcela relativa às despesas administrativas gerais que aparecem nos balanços de cada órgão da área educacional foi distribuída de acordo com o peso do gasto e da matrícula de cada nível e modalidade, em cada ano. Entende-se que esse procedimento permite ter uma melhor aproximação possível do verdadeiro valor de gasto por nível e modalidade.

6. O conceito econômico apresenta a Carga Tributária Bruta (Ств) como o quociente entre a receita tributária total e o valor do Produto Interno Bruto (PIB) do país, em determinado exercício fiscal. А ств é o que cada esfera de governo (União, Estados e Municípios) arrecada, isto é, a receita sem deduçôes das transferências ao setor privado da economia, como os subsídios, benefícios da seguridade social e os saques do Fundo de Garantia por Tempo de Serviço (FGTS).

7. Os dados sobre a arrecadação tributária são provenientes do estudo publicado pela SRF, sobre a Carga Tributária Bruta, e podem ser encontrados no site da Receita Federal: $<w w w . r e c e i t a . f a z e n d a . g o v . b r>$

\section{Referências bibliográficas}

ALMEIDA, I.C. Gastos com educação no período de 1994 a 1999. Revista Brasileira de Estudos Pedagógicos, Brasília, DF, v. 82, n. 200/ 201/202, p. 137-198, jan./dez. 2001.

BRASIL. Constituição (1988). Constituição da República Federativa do Brasil. Brasília, DF: Senado, 1988.

BRASIL. Lei n. 9.394, de 20 de dezembro de 1996. Estabelece as diretrizes e base da educação nacional. Diário Oficial da União, Brasília, DF, 23 dez. 1996. p. 27894.

BRASIL. Ministério da Educação. Plano Nacional de Educação. Brasília, DF: MEC/INEP, 2001.

CASTRO, J. Financiamento da educação: necessidades e possibilidades. Brasília, DF: IPEA, 2004. (mimeo.).

CASTRO, J.; CARDOSO, J. Políticas sociais no Brasil: gasto social do governo federal de 1988 a 2002. In: JACCOUD, L. et al. (Org.). Questão social e políticas sociais no Brasil contemporâneo. Brasília, DF, IPEA, 2005. 
CASTRO, J.; FERNANDES, M.A. Sistema de informaçôes sobre os gastos públicos da área de educação - SIGPE: diagnóstico para 1995. Brasília, DF: IPEA, 1999. (Texto para discussão, n. 674).

CASTRO, J.; SADECK, F. Financiamento do gasto em educação das três esferas em 2000. Brasília, DF: IPEA, 2003. (Texto para discussão, n. 955).

CASTRO, J.; VAZ, F. Gastos das familias com educação. In: Gastos das familias. Brasília, DF, IPEA, 2007.

CASTRO, J. et al. Análise da evolução e dinâmica do gasto social federal: 1995-2001. Brasília, DF: IPEA, 2003. (Texto para discussão, n. 988).

CASTRO, J. et al. Gasto social e politica macroeconómica: trajetórias e tensôes no período 1995-2005. Brasília, DF: IPEA, 2007. (Texto para discussão, s/n).

FERNANDES, M.A. Mensuração do gasto público social: a metodologia desenvolvida na Diretoria de Estudos Sociais do IPEA. Brasília, DF: IPEA, 2000. (mimeo.).

FERNANDES, M.A. et al. Dimensionamento e acompanhamento do gasto social federal, 1994-1996. Brasília, DF: IPEA, 1998a. (Texto para discussão, n. 547)

FERNANDES, M.A. et al. Gasto social das três esferas de governo: 1995. Brasília, DF: IPEA, 1998b. (Texto para discussão, n. 598)

INSTITUTO NACIONAL DE ESTUDO DE PESQUISAS EDUCACIONAIS (INEP). Relatório do grupo de trabalho sobre financiamento da educação. Revista Brasileira de Estudos Pedagógicos, Brasília, DF, v. 82, n. 200/201/202, p. 117-135, jan./dez. 2001.

INSTITUTO NACIONAL DE ESTUDO DE PESQUISAS EDUCACIONAIS (INEP). PISA 2000 Relatório Nacional. Brasília, DF, dez. 2001. Disponível em: <www.inep.gov.br/internacional/pisa>. Acesso em: jul. 2005. 